\title{
Observation of wave generation and non-local perturbations in the atmosphere during the passage of a typhoon
}

\author{
V K Anandan ${ }^{1, *}$, V N Sureshbabu ${ }^{1}$, C J Pan ${ }^{2}$ and S Vijayabhaskara RaO ${ }^{3}$ \\ ${ }^{1}$ ISTRAC, Indian Space Research Organisation, Bangalore 560 058, India. \\ ${ }^{2}$ Institute of Space Science, National Central University, Chung-Li, 32054, Taiwan. \\ ${ }^{3}$ Department of Physics, SV University, Tirupati 517 502, India. \\ ${ }^{*}$ Corresponding author. e-mail: anandanvk@hotmail.com
}

\begin{abstract}
During the passage of typhoon Kujira in April 2003 near to the northeast of Taiwan, atmospheric radar at Chung-Li $\left(24^{\circ} 58^{\prime} \mathrm{N}, 121^{\circ} 11^{\prime} \mathrm{E}\right)$ was continuously operated. The data collected from profiler radar was used to investigate the impact of typhoon on generating waves and other atmospheric disturbances. Result showed that the typhoon and the associated wind disturbances can generate atmospheric waves with varied periodicity even when the core was far away from the land. The waves were quite prominent when the core was closer to the mountain. Observations show that these waves propagate vertically upward for many kilometers and getting trapped in higher altitudes. The radar reflectivity at the tropopause during the event showed that stable layer structure was very weak. Further, the enhancement in ozone measurement at the ground level was observed when the typhoon was near to radar site.
\end{abstract}

\section{Introduction}

VHF radar techniques have been extensively used for studying the wave activities in atmosphere. Larsen and Röttger (1982) and Röttger (2000) gave detailed review of the observation made by the radar for clear air and meteorological purposes. Today, the mesoscale or convective-scale meteorological disturbances are of much interest to researchers and of much importance to forecasters. Now it is well known that immediate changes in thermodynamics of lower atmosphere have the potential to trigger a spectrum of gravity waves. For instance, number of observations and theoretical studies reveal that the tropical convections (Walterscheid et al. 2003; Alexander et al. 2006), weather fronts (Eckermann and Vincent 1993), orography (Tsuda et al. 1989) and thunderstorms and lightening (Taylor and Hapgood 1988), are the potential sources for wave activity in the atmosphere. It was proved that any kind of sudden enhancement of lower atmospheric warming can be the cause of gravity waves propagating up to the mesospheric region (Dunkerton and Butchart 1984). The certain observation suggests that the sudden enhancement of warming in the troposphere over continental landmass could be a strong potential source of wave activity (McLandress et al. 2000).

An understanding of the various processes associated with the convective phenomena is so important. At tropical latitudes, the convective phenomena are more frequent and influence the stratospheretroposphere exchange process (TSE). The tropical convection phenomena are expected to play a significant role in TSE (Holton and Matsuno 1984).

Keywords. Typhoon; atmospheric waves; tropopause; radar remote sensing; meteorology and atmospheric dynamics. 
The atmospheric stable layer structures associated with the tropical tropopause also play an important role in TSE. Such structures are expected to undergo considerable changes (depending upon the strength of the convection) during the passage of a convection cell over the radar site.

There are number of studies that have been carried out using the radar on mesoscale phenomena like typhoon. Sato et al. (1991) observed the short period wind fluctuations up to $24 \mathrm{~km}$ and prominent wave with vertical wavelength of $2-4 \mathrm{~km}$ when typhoon passed near the MU radar site. VHF radar signals, during the passage of the mesoscale convective systems, may sometimes consist of spectral traces which arise due to turbulence backscatter and precipitation (Yoe et al. 1992). Another study by Sato (1993) reported the significant difference in wave activity and the associated statistical characteristics before and after the typhoon. The waves generated by airflow over topography, their impact on various atmospheric dynamics and global circulation model were extensively reported in literature (Mitchell et al. 1990; Ralph et al. 1992; Caccia et al. 1997; Worthington and Thomas 1997; Worthington 1998; Rechou et al. 1999). Moreover, it has been realized that the lower atmospheric perturbations often produce measurable effects in the middle and upper atmosphere.

There are strong theoretical and observational evidences that thunderstorms represent significant sources of short period, small-scale gravity wave activity throughout the middle and upper atmosphere (Fritts and Alexander 2003; Snively and Pasko 2008). Mechanical oscillations of air due to penetrative convection at thundercloud tops are believed to be a dominant forcing mechanism of small-scale gravity waves (Pierce and Coroniti 1966; Stull 1976; Fovell et al. 1992). To corroborate the process, simulation studies had been carried out in numerous modelling studies for squall-line and isolated convective sources (Alexander et al. 1995; Piani et al. 2000; Horinouchi et al. 2002). Evidence of thunderstorm generated waves includes rocket observations of mesospheric heating above thunderstorms (Taylor 1979), and radar detection of upward traveling gravity waves at stratospheric altitudes above thunderstorms (Larsen et al. 1982). Ground-based (Taylor and Hapgood 1988; Sentman et al 2003) and satellite-based (Dewan et al. 1998) observations of stratospheric and mesospheric nightglow emissions have also revealed coherent circular gravity wave structure, clearly associated with underlying thunderstorm activity.

The recent study (Das et al. 2012) discussed short-period gravity waves associated with the passage of tropical cyclone using mesospherestratosphere-troposphere (MST) radar located at Gadanki $\left(13.5^{\circ} \mathrm{N}, 79.2^{\circ} \mathrm{E}\right)$. The study demonstrated that the maximum amplitude of gravity wave was observed in the upper troposphere and lower stratosphere (UTLS) regions due to which periodic updrafts and downdrafts were observed, that weakens the stability of tropopause. Also, certain studies (Niranjan Kumar and Ramkumar 2008) were made on the characteristics of inertia-gravity waves generated in the lower troposphere during deep depression developed over the Bay of Bengal. The study indicated that the low-pressure system could generate inertia gravity waves, propagating outward from the core of the depression.

In the present study, the series of vertical observations of radar SNR are used to study the changes in the atmospheric stable layer structures associated with the tropopause region, during the period of typhoon Kujira near Taiwan east coast. Such structures are observed to be prominent after the peak convective activity. More observations of this kind would help in establishing the relationship between the energy associated with the convection and changes in structure of the atmosphere and that of the stable layer structure near the height of the tropical tropopause. Such observations of echo provide evidence of weakening of the tropopause associated stable layer structures. Also, the impact of such wave activity on stable layers and tropopause is discussed by comparing the radar reflectivity and ozone measurement on the ground level.

\section{Observation and data analysis}

Figure 1 shows the track of the typhoon Kujira (No. 2, 2003) observed during 11-25 of April, 2003. The typhoon was moving along northwest direction during 19-23 of April and then it took a trajectory towards northeast and decayed (shown in figure 2). Figure 3 shows the horizontal wind and direction obtained from radiosonde observations over Hualien station situated along east of radar site and in the mountain region. The observation shows that the strong wind below about $7 \mathrm{~km}$ altitude (associated with the circulation of typhoon) is transverse to the mountain during 1924 of April and the wind has changed its direction from 24 April, 1200Z onwards. Cold point tropopause height reported by radiosonde observation is marked as triangle on the wind profile.

The VHF radar operating at $52 \mathrm{MHz}$ is situated at northwest of the mountains and around $50 \mathrm{~km}$ away from the east coast. The range resolution was $300 \mathrm{~m}$ with the observation window of $1.8-20 \mathrm{~km}$. The inter pulse period and coherent integrations were chosen for observing maximum radial velocity of $\pm 8.5 \mathrm{~ms}^{-1}$ in the unambiguous range. Further, it could be possible to obtain a data frame 


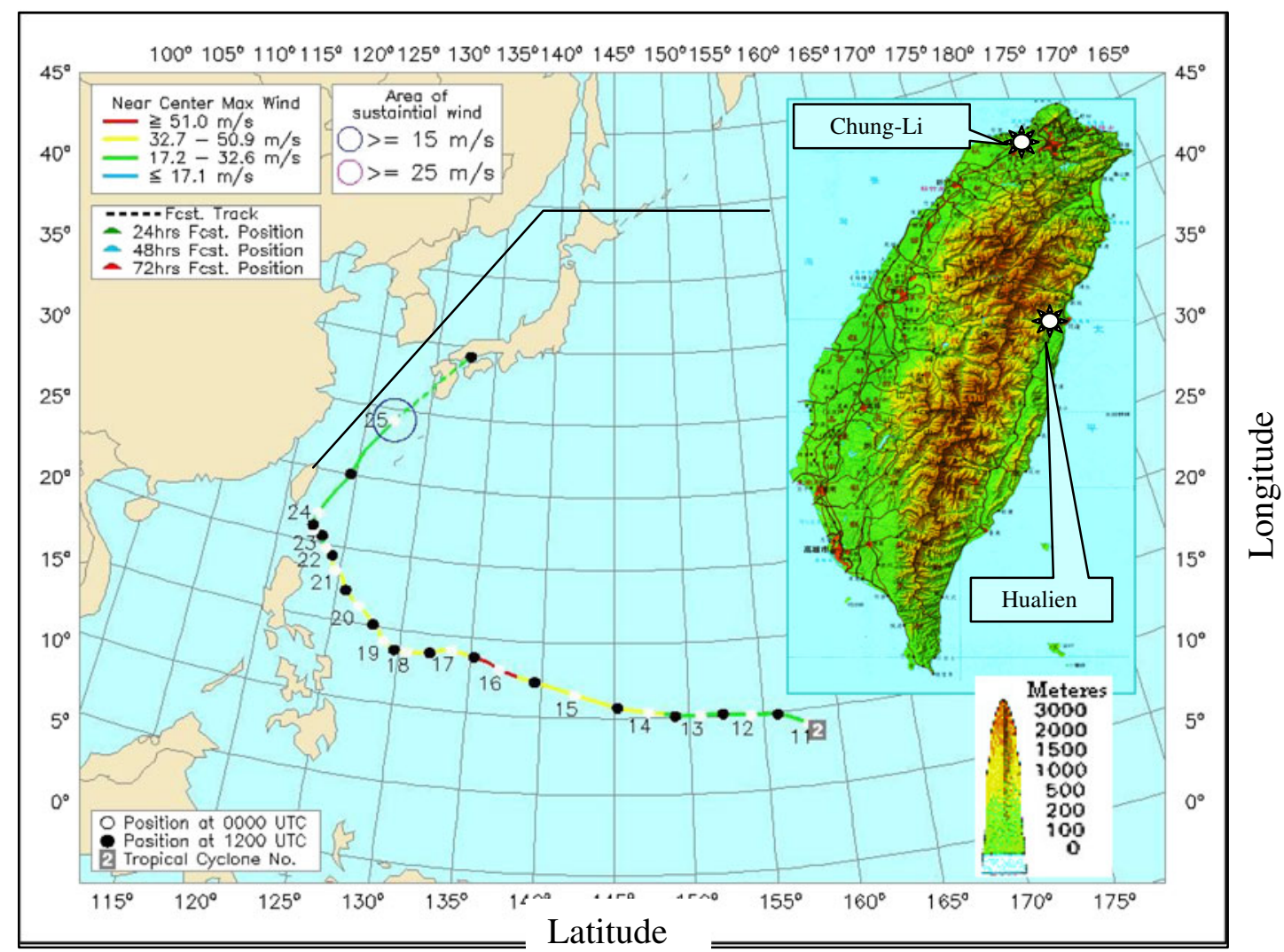

Figure 1. Topography of Taiwan and trajectory of Kujira typhoon.

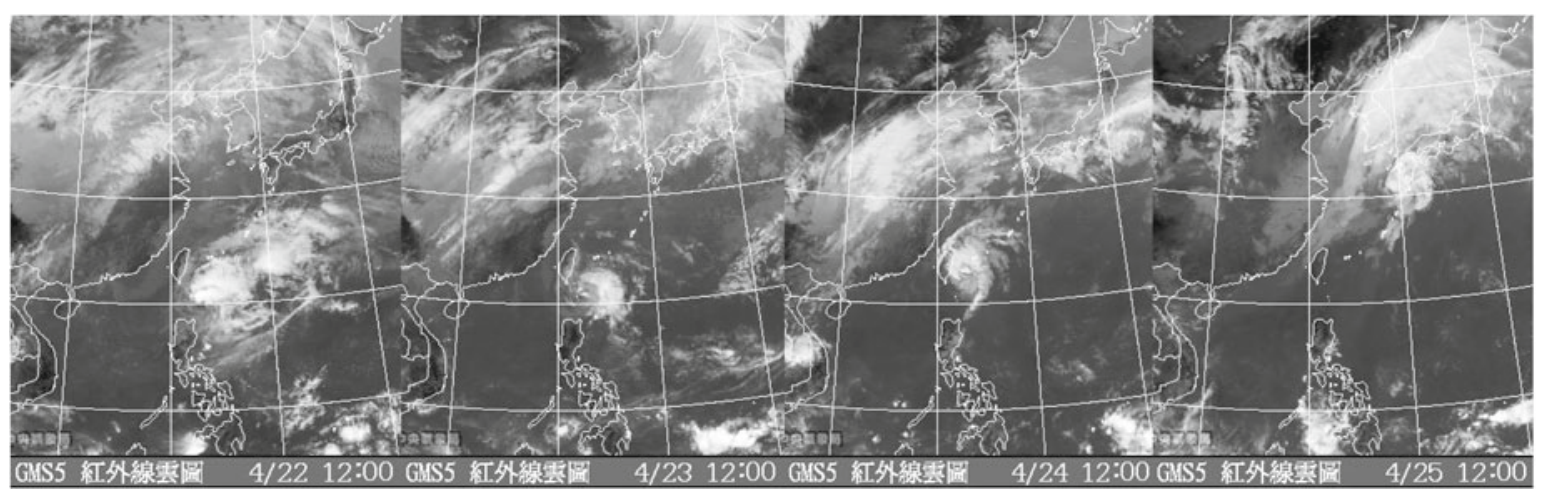

22 April 2003

23 April 2003

24 April 2003

25 April 2003

Figure 2. Satellite images of Kujira typhoon from 22-25 April 2003.

for every 40 seconds. Since the radar was operated with only vertical beam, the horizontal velocities from the observation could not be deduced. The radiosonde data was used for deriving horizontal wind velocity and scorer parameter. The data was analyzed to estimate the first three lower order moments, i.e., power, mean Doppler velocity and velocity width. Since the sensitivity of VHF Chung$\mathrm{Li}$ radar is small compared with large scale MST radars elsewhere, the signal-to-noise ratio (SNR) falls off rapidly with range and it is not possible to get continuous echoes throughout the observation window. However, there were possibilities for obtaining echoes of vertical incidence from stable layers, tropopause and the layers with refractive index fluctuations. So, an attempt has been made to extract the signal up totropopause by keeping the observation window up to $20 \mathrm{~km}$. Here, a realistic minimum SNR around $-16 \mathrm{~dB}$ was taken for considering the echoes and wave analysis. The mean Doppler velocity obtained for 24 hours is subjected to wave analysis for finding the periodicity. In order 


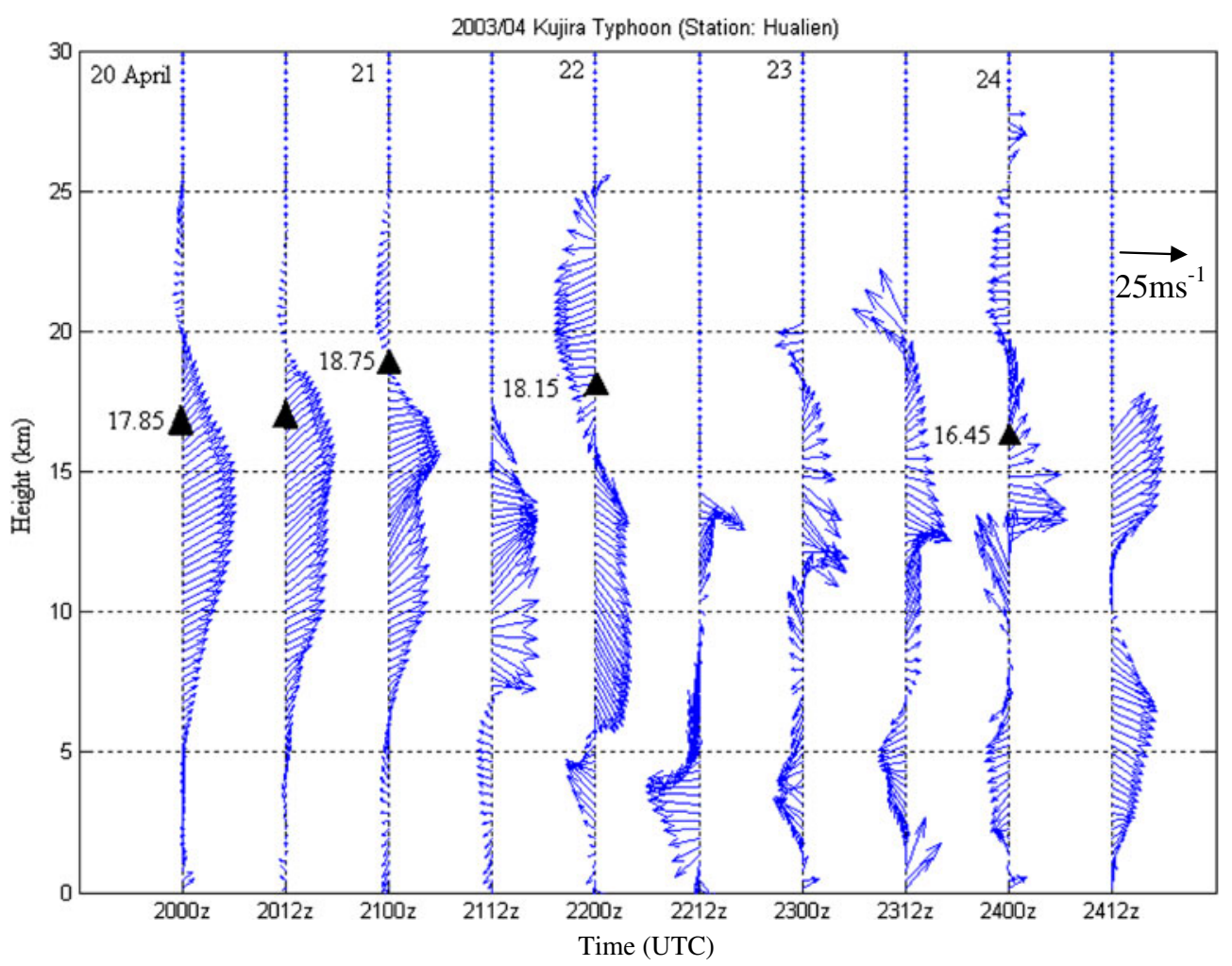

Figure 3. Wind profile observed using radiosonde from 20-24 April 2003 at Hualien station. Triangle represents the coldpoint tropopause height.

to compare the wave activity observed during the typhoon and the normal days, radar data collected 19-20 of May, 2003 was also analyzed.

The ground ozone measurement from Kuan Yin and $\mathrm{Wu}$ Chuan station near to the radar site was analyzed to observe any change in ozone level due to weakening of tropopause by the typhoon passage.

\section{Results and discussion}

Figure 4 shows the Range-Time-Intensity (RTI) plot of radar echoes observed during 19-24 of April, 2003. It is observed that there is fall in intensity of received echoes when the typhoon is nearing towards the land on 21-23 of April and there is rise in intensity of the received echoes when typhoon is departing away from the site and migrating towards northeast. Vertical velocity estimated from the observed data is subjected to Fourier analysis for understanding the prominent waves present in atmosphere during the passage of typhoon. Figure 5(a-f) shows the plots of wave analysis for the period of 24 hours data during the typhoon period. Prominent waves observed between 10 and 30 minute periods up to the altitude of $9 \mathrm{~km}$ are shown in this figure. The intensity of different periods of wave is observed to enhance from 19th April onwards and reaches its maximum on 21-22 April during which typhoon was strong and closer to the radar site. After that the intensity of the waves has reduced as seen in figure 5(f). Mitchell et al. (1990) showed that the vertical velocity of the mean wind, temperature profile and the geometry of the generating obstacles govern the formation, amplitude and periods of orographically generated waves. The formation of waves depends on the vertical profile of the scorer parameter $\ell$ (Scorer 1949), where

$$
\ell^{2}(z)=\frac{g \beta}{U^{2}}-\frac{1}{U} \frac{d^{2} U}{d Z^{2}}
$$

$U$ is the horizontal wind velocity normal to ridge and $\beta$ is the static stability given by $\theta^{-1} d \theta / d z$ where $\theta$ is the potential temperature. The second term in equation (1) corresponds to the curvature in $U$ term and it is negligible at higher altitudes. The first term in the equation is derived from mean buoyancy frequency, which is the primary indicator of the stability of the atmospheres to vertical displacement (Houze 1993). Figure 6(a-f) shows height profiles of scorer parameter $\ell$ derived during 19-24 of April using radiosonde at Hualien. Plots were drawn only up to $17 \mathrm{~km}$ due to nonavailability of wind or pressure data from the radiosonde. The $\ell$-profile is characterized by rapid decrease in the scorer parameter with height. The rapid decrease of $\ell$ with height in the lower 


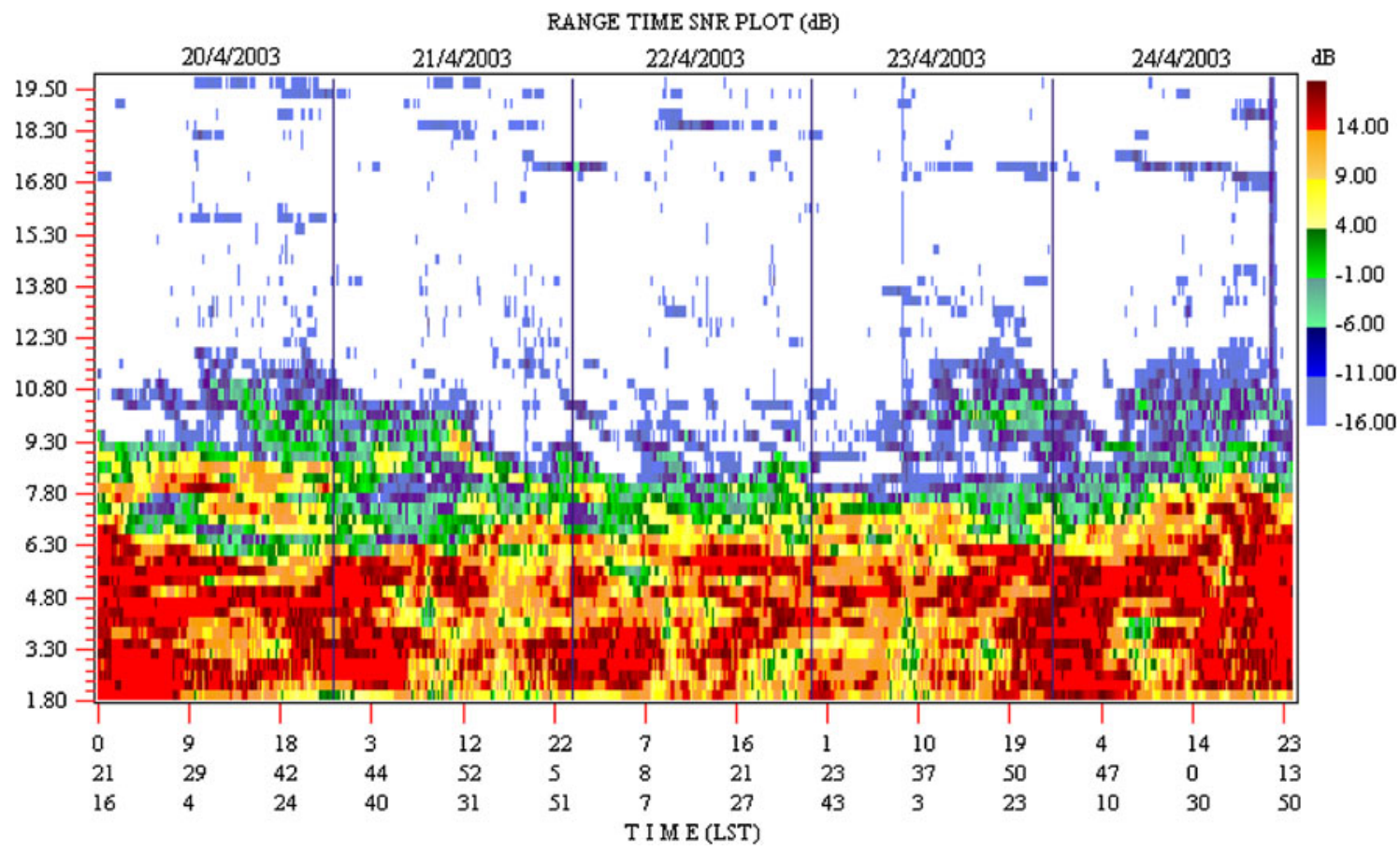

Figure 4. RTI plot of radar back-scattered signals observed on 20-24 April 2003.

19 April 2003
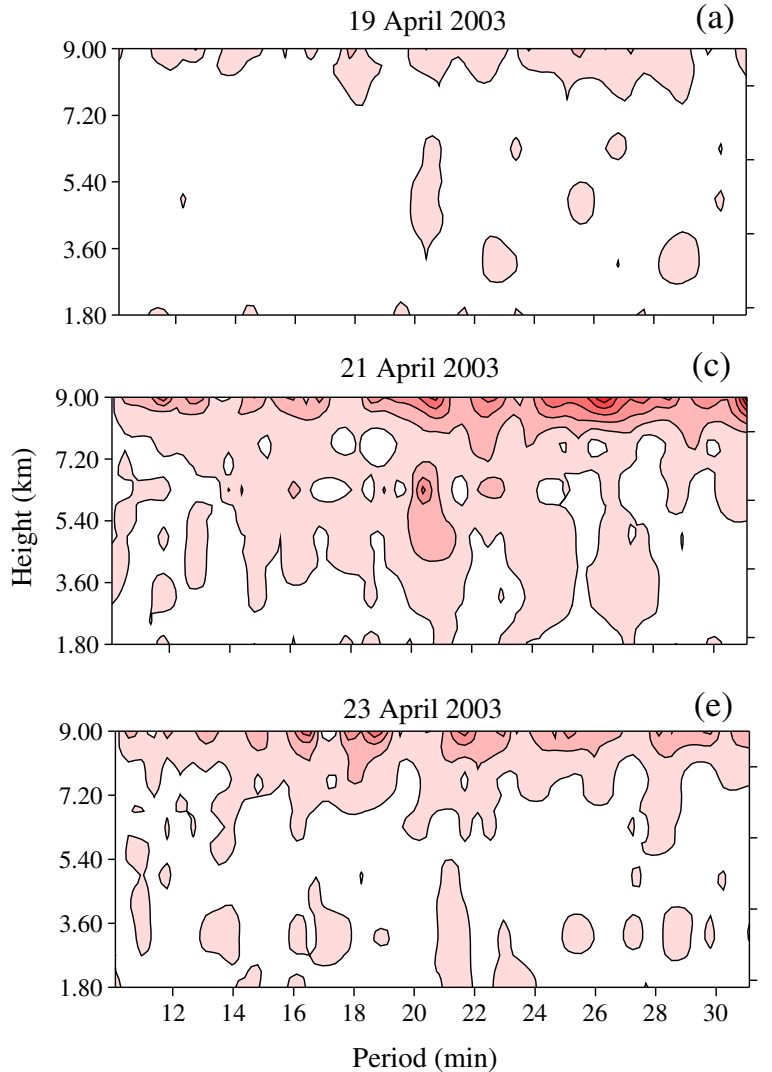

20 April 2003

(b)

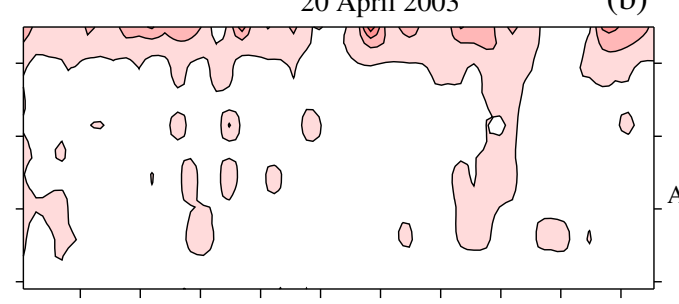

(d)
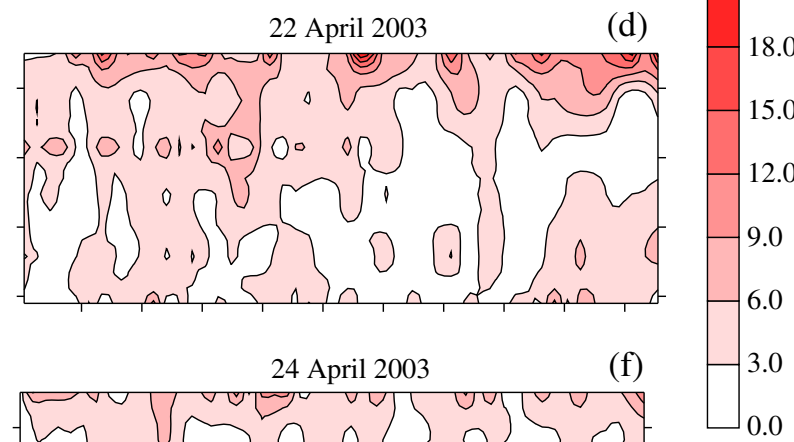

Figure 5. Atmospheric waves of different periodicity at different altitudes observed from 19 to 24 April, 2003 by VHF radar at Chung-Li.

troposphere sets up as a wave-guide in which the wave amplitudes can become large and the waves are more or less effectively trapped (Ralph et al.
1992). The vertical propagation is also controlled by the mean flow of wind where it depends on the presence or the absence of the critical layers. 

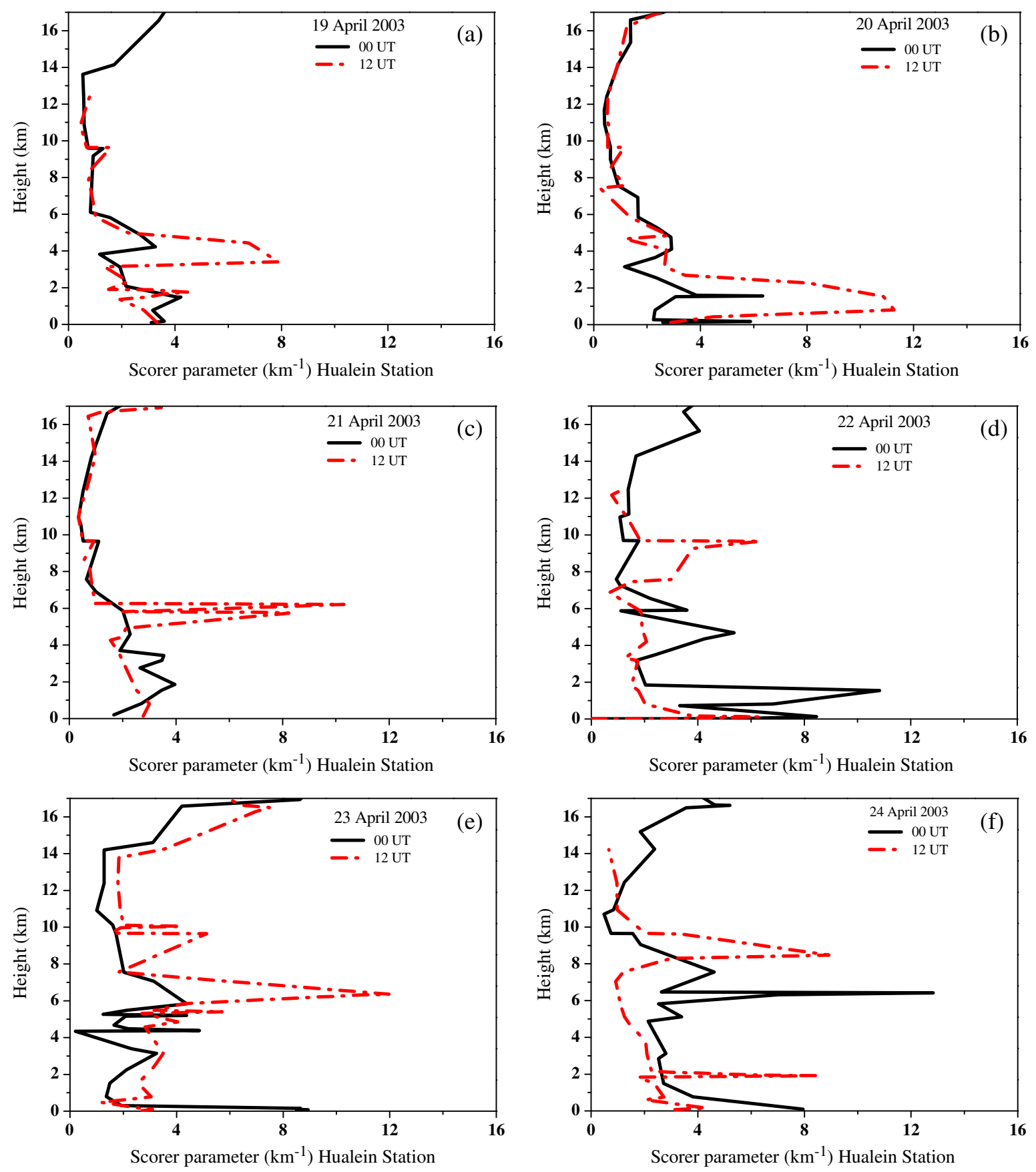

Figure 6. Scorer parameter derived from radiosonde observation at Hualien station from 19 to 24 April 2003.

If the mean wind vanishes or direction of mean wind is perpendicular to the wave propagation, the critical layer appears, that leads to the absorption of wave activity (Rechou et al. 1999). During 19-22 of April, the scorer parameter decreases sharply between 3 and $6 \mathrm{~km}$ and remains low up to tropopause. Considering the wind observation, it is seen that wind direction changes around $18 \mathrm{~km}$ from NE at the lower levels to NW above the tropopause. This is prominent on 22 of April and radar also shows strong wave activity with large amplitude at higher altitudes. This may lead to trapping of wave by a critical layer. On 23 and 24 of April, radar observation shows the reduced wave activity compared to previous day. Typhoon has very less forward movement on 23 April and changes its direction from NW to NNE on 24 April. The observation also shows very strong wind in lower atmosphere below $5 \mathrm{~km}$ then decreases up to $10 \mathrm{~km}$ and again increases by changing the direction. During these days, the scorer parameter is observed to be less in the altitutes between 9 and $14 \mathrm{~km}$. This can be expected to lead trapping of waves under the tropopause height. 
Balachandran (1980) described observations of both long period waves $(3 \mathrm{~h})$ and short period waves (down to $290 \mathrm{~s}$ ) generated by thunderstorms in the northeastern United States. Wave trapping in a waveguide where a critical layer was present at the tropopause permitted propagation of the oscillations over $1000 \mathrm{~km}$ with remarkable stability in the shape and amplitude of the waveform. Shear instabilities of thunderstorm outflows were identified as the most likely source of the waves. It was proposed that the waves in turn generated other thunderstorms by uplifting conditionally unstable air. Das et al. (2012) reported short-period gravity waves associated with the passage of tropical cyclone using mesospherestratosphere-troposphere (MST) radar located at Gadanki $\left(13.5^{\circ} \mathrm{N}, 79.2^{\circ} \mathrm{E}\right)$. They observed stratospheric gravity wave is found to have a periodicity of $\sim 42 \mathrm{~min}$ and an enhancement of vertical momentum flux of order $\sim-0.6 \mathrm{~m}^{2} / \mathrm{s}^{2}$. This is attributed to the cyclone-generated gravity waves. The obstacle effect is found to be the generative mechanism for the observed gravity waves associated with the tropical cyclone. With reference to previous reported studies, this observation also strongly supports the obstacle effect as shown in the topography of the radar site and shear instabilities of thunderstorm outflows are the probable cause for the generation of waves with prominent periods of 10-30 min.
The radar observation during the typhoon is compared with normal days. The observation shows that the wave is being generated in the disturbed days and increases its amplitude with height up to the end of observation window possible with radar. Normal day observations were taken on 19-20 of May, 2003. Figure 7 shows the RTI plot of radar observation and figure 8 shows the wave analysis plot during normal days. During these days, radiosonde observation was not available to derive the scorer parameter. Figure 7 shows a good SNR up to $11 \mathrm{~km}$ on both days and there is no waves observed similar to that of observed during typhoon. The height profile of scorer parameter and the wave amplitude during the typhoon reveal that the waves are generated during the mesoscale disturbance and get trapped in the lower atmosphere.

It is expected that the stable layers and tropopause are highly aspect sensitive in the normal atmospheric condition and can give more back-scattered signals. In the comparison between radar observation and radiosonde temperature profile, Jain et al. (2000) showed that the echo power usually increases at altitudes near tropopause and stable layers exist. During the typhoon period around the tropopause height $17-19 \mathrm{~km}$ as reported in radiosonde (figure 3 ), there were weak echoes, which are not visible in the radar observation as shown in figure 4. During the normal day,

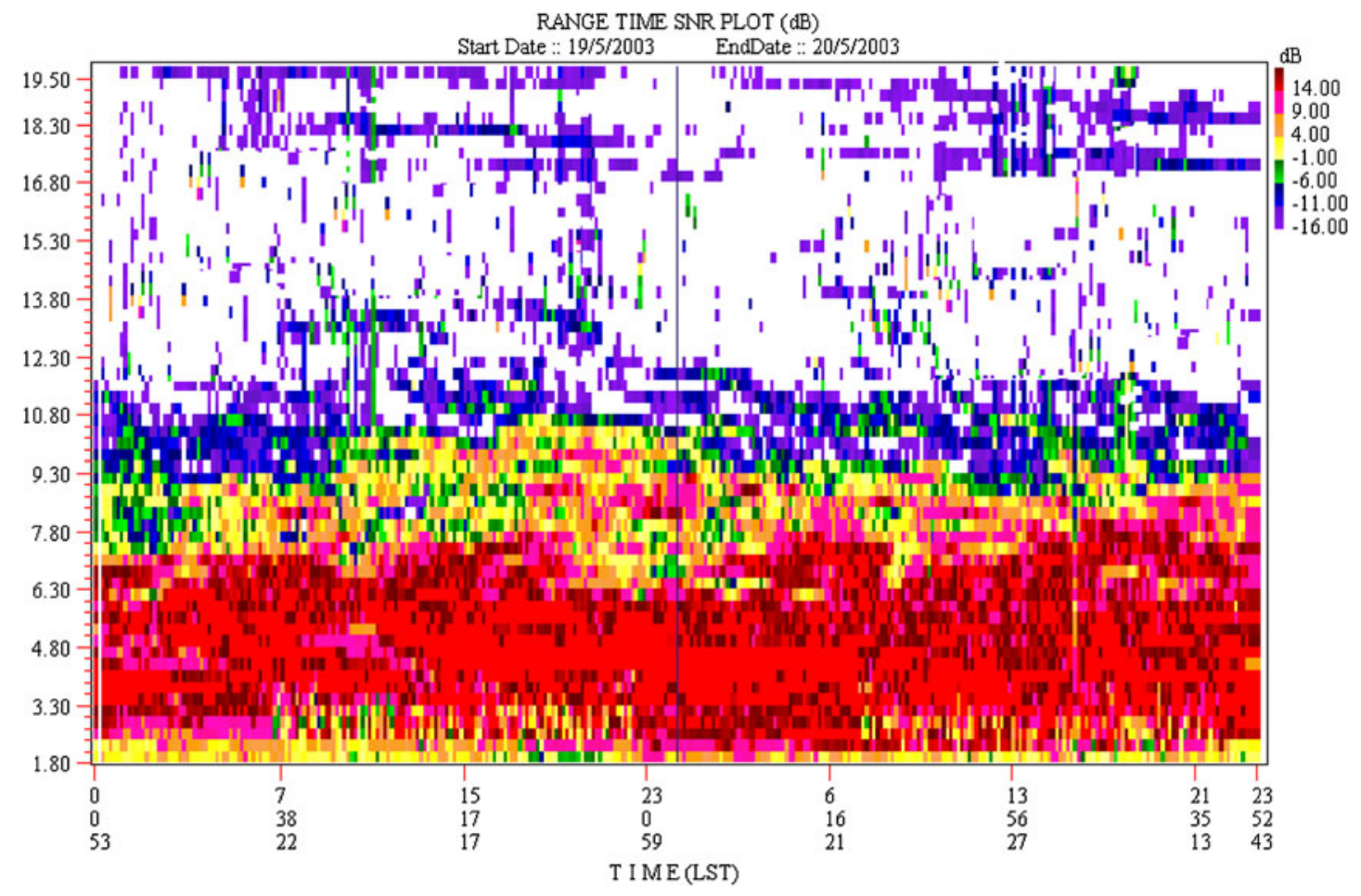

Figure 7. RTI plot of radar back-scattered signal observed on 19 and 20 May 2003. 

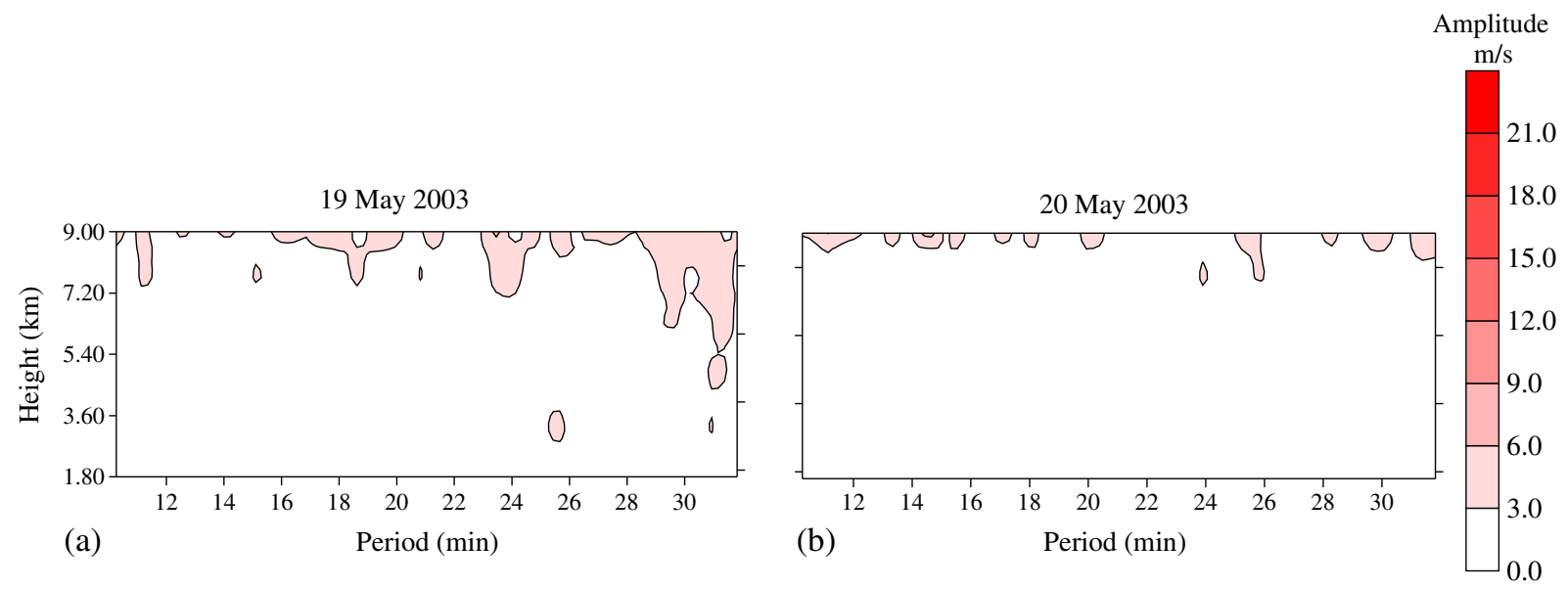

Figure 8. Atmospheric waves of different periodicity at different altitudes observed from 19 to 20 May, 2003 by VHF radar at Chung-Li.

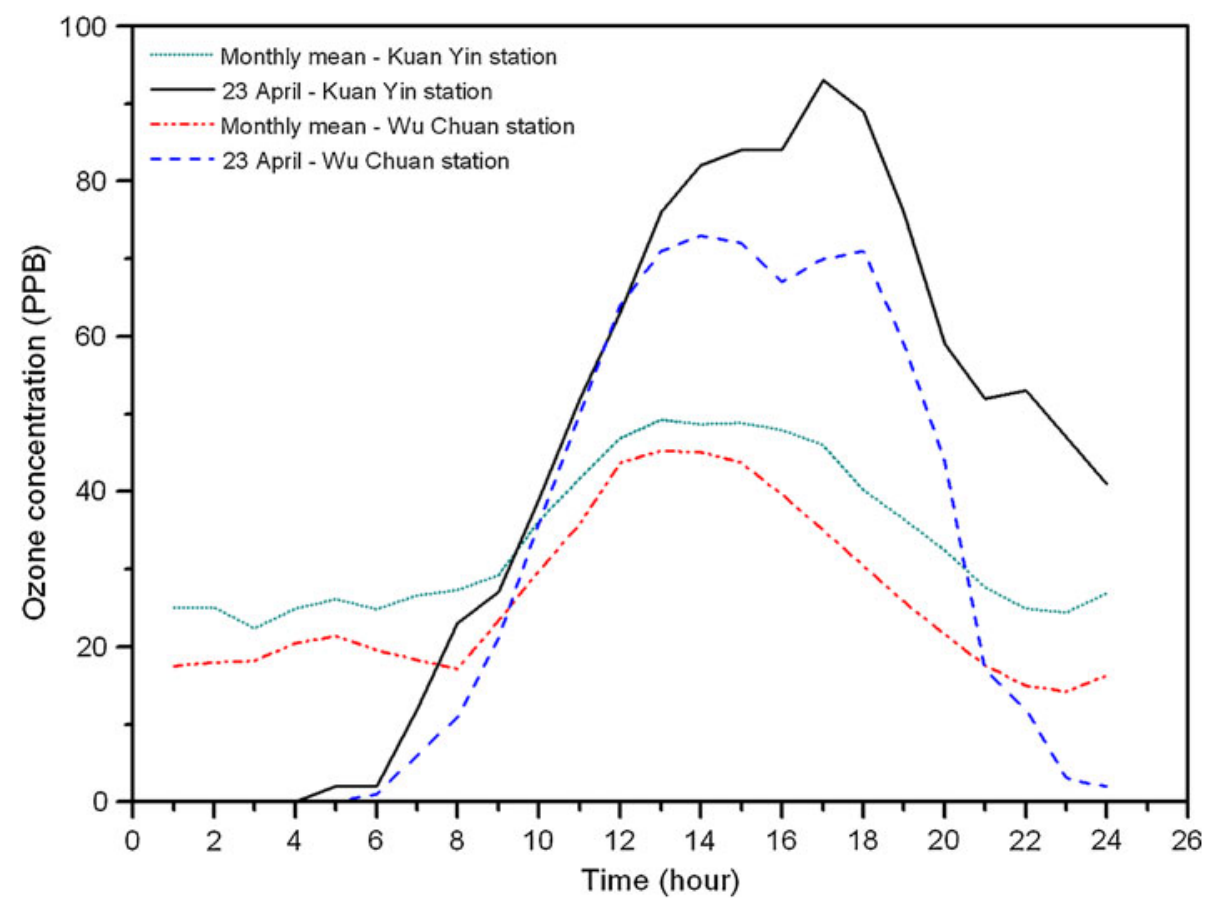

Figure 9. Ground ozone concentration observed at two places near to the radar site. Mean ozone concentration in April 2003 and observation on 23 April 2003 is plotted.

3-4 dB higher signal strength is observed in backscattered signal compared to the disturbed days, which is shown in figure 7 . In the study of mesoscale convective event, by comparing radar reflectivity profile, Jain et al. (2000) observed the breaking or weakening of tropopause compared to before and after the event. While deducing the turbulence energy dissipation rate, Worthington (1998) concluded that wave breaking as the most important source of turbulence in lower atmosphere. Present observation seems to lead the similar result that the tropopause is weakened due to turbulence generated at the higher altitudes due to the breaking of atmospheric waves during the passage of typhoon.

Figure 9 shows two ozone concentration observations on the ground level near the radar site. There is a higher concentration of ozone reported during the passage of typhoon and it is more prominent on 23 April. The major increase of ozone concentration between stratosphere and troposphere occurs almost below the tropopause found from temperature profiles. There are cases where clear gradient in temperature and ozone concentration were not visible (called as indefinite tropopause). The indefinite tropopause is characterized by large 
ozone concentration in lower atmosphere (Bethan et al. 1996). Using the simultaneous observation of ozonesonde and radar, Mandal et al. (1998) also observed that there is stratosphere-troposphere ozone exchange along with weakness in the radar back-scattered signal at tropopause. Even though it is not possible to prove without ozone profile for complete altitude, the missing of clear gradient in temperature and ozone concentration along with the weakness or breaking of the tropopause may be attributed to non-local perturbations. Also, the observation shown here suggests a close link between the weakening of tropopause and the possible enhancement of ozone concentration in ground level.

\section{Conclusion}

Radar observation during the passage of typhoon shows the evidence of generation of atmospheric waves. The increase in amplitude of waves with height leads to the evidence of possible wave breaking below tropopause. The waves are generated even when the core of the typhoon is 250 $300 \mathrm{~km}$ away from the mountains and is persisted during the trajectory, which is transverse to the mountains. The scorer parameter shows significant change during these days and decreases fast as the height increases, which lead to the evidence of wave trapping at higher altitudes. It is suggested that obstacle effect as shown in the topography of the radar site and shear instabilities of thunderstorm outflows may be the probable causes for the generation of waves with prominent periods of $10-30 \mathrm{~min}$. It is also observed that the reflectivity profile around tropopause is weak during the typhoon. The enhancement of ozone at ground level is observed during this period and correlated to the weak tropopause reflectivity. This needs to be investigated with more observations of similar type.

\section{References}

Alexander M J, Holton J R and Durran D R 1995 The gravity wave response above deep tropical convection in a squall line simulation; J. Atmos. Sci. 52(12) 2212-2226.

Alexander M J, Richter J H and Sutherland B R 2006 Generation and trapping of gravity waves from convection with comparison to parameterization; J. Atmos. Sci. 63 2963-2977.

Balachandran N K 1980 Gravity waves from thunderstorms; Mon. Weather Rev. 108 804-816.

Bethan S, Vaughan G and Reid S J 1996 A comparison of ozone and thermal tropopause heights and the impact of tropopause definition on quantifying the ozone content of the troposphere; Quart. J. Roy. Meteorol. Soc. 122 929-944.
Caccia J L, Benech B and Klaus V 1997 Space-time description of nonstationary trapped lee waves using ST radars, aircraft and constant volume balloons during the PYREX experiments; J. Atmos. Sci. 54 1821-1833.

Das S S, Uma K N and Das S K 2012 MST radar observations of short-period gravity wave during overhead tropical cyclone; Radio Sci. 47, doi: 10.1029/2011RS004840.

Dewan E M, Picard R H, O'Neil R R, Gardiner H A, Gibson J, Mill J D, Richards E, Kendra M and Gallery W O 1998 MSX satellite observations of thunderstormgenerated gravity waves in the mid-wave infrared images of the upper stratosphere; Geophys. Res. Lett. 25(7) 939-942.

Dunkerton T J and Butchart N 1984 Propagation and selective transmission of internal gravity waves in a sudden warming; J. Atmos. Sci. 41 1443-1460.

Eckermann S D and Vincent R A 1993 VHF radar observations of gravity-wave production by cold fronts over southern Australia; J. Atmos. Sci. 50 785-806.

Fovell R, Durran D and Holton J R 1992 Numerical simulation of convectively generated stratospheric gravity waves; J. Atmos. Sci. 49(16) 1427-1443.

Fritts D C and Alexander M J 2003 Gravity wave dynamics and effects in the middle atmosphere; Rev. Geophys. 41(1) 1003, doi: 10.1029/2001RG000106.

Holton J R and Matsuno T 1984 Troposphere-stratosphere exchange of trace constituents: The water vapor puzzle; Terra Scientific Publishing Co., pp. 369-385.

Horinouchi T, Nakamura T and Kosaka J 2002 Convectively generated mesoscale gravity waves simulated throughout the middle atmosphere; Geophys. Res. Lett. 29(21) 2007, doi: 10.1029/2002GL016069.

Houze R A Jr 1993 Cloud Dynamics (San Diego, Calif.: Academic Press, Inc.), 45p.

Jain A R, Rao Y J, Patra A K, Rao P B, Viswanathan G and Subramanian S K 2000 Observations of tropical convection events using Indian MST radar: First results; Quart. J. Roy. Meteorol. Soc. 126 3097-3115.

Larsen M F and Röttger J 1982 VHF and UHF Doppler radars as tools for synoptic research; Bull. Am. Meteorol. Soc. 63 996-1008.

Larsen M F, Swartz W E and Woodman R F 1982 Gravity-wave generation by thunderstorms observed with a vertically-pointing $430 \mathrm{MHz}$ radar; Geophys. Res. Lett. 9(5) $571-574$.

Mandal T K, Cho J Y N, Rao P B, Jain A R, Peshin S K, Srivastva S K, Bohra A K and Mitra A P 1998 Stratosphere-troposphere ozone exchange observed with the Indian MST radar and simultaneous balloon-borne ozonesonde; Radio Sci. 33(4) 861-893.

McLandress C, Alexander M J and Wu D L 2000 Microwave Limb Sounder observations of gravity waves in the stratosphere: A climatology and interpretation; J. Geophys. Res. 105 11947-11967.

Mitchell R M, Cechet R P, Turner P J and Elsum C C 1990 Observation and interpretation of wave clouds over Macquarie Island; Quart. J. Roy. Meteorol. Soc. 116 741-752.

Niranjan Kumar K and Ramkumar T K 2008 Characteristics of inertia-gravity waves over Gadanki during the passage of a deep depression over the Bay of Bengal; Geophys. Res. Lett. 35, doi: 10.1029/2008GL033937.

Piani C, Durran D, Alexander M J and Holton J R 2000 A numerical study of three-dimensional gravity waves triggered by deep tropical convection and their role in the dynamics of the QBO; J. Atmos. Sci. 57(22) 3689-3702.

Pierce A D and Coroniti S C 1966 A mechanism for the generation of acoustic-gravity waves during thunderstorm formation; Nature 210(5042) 1209-1210. 
Ralph F M, Crochet M and Venkateswaran S V 1992 A study of mountain lee waves using clear-air radar; Quart. J. Roy. Meteorol. Soc. 118 597-627.

Rechou A, Barabash V, Chilson P, Kirkwood S, Saitskaya $\mathrm{T}$ and Stebel K 1999 Mountain wave motions determined by the Esrange MST radar; Ann. Geophys. 17 957-970.

Röttger J 2000 ST radar observations of atmospheric waves over mountainous areas: A review; Ann. Gephys. 18 750-765.

Sato K 1993 Small-scale wind disturbances observed by the MU radar during the passage of typhoon Kelly; J. Atmos. Sci. 50 518-537.

Sato T, Naoki Ao, Yamamoto M, Fukao S, Tsuda T and Kato S 1991 A typhoon observed with the MU radar; Mon. Weather Rev. 119 755-768.

Scorer R S 1949 Theory of waves in the lee of mountains; Quart. J. Roy. Meteorol. Soc. 75 4156.

Sentman D D et al. 2003 Simultaneous observations of mesospheric gravity waves and sprites generated by a midwestern thunderstorm; J. Atmos. Sol.-Terr. Phys. 65 $537-550$.

Snively B and Pasko V P 2008 Excitation of ducted gravity waves in the lower thermosphere by tropospheric sources Jonathan; J. Geophys. Res. 113 A06303, doi: 10.1029/ 2007JA012693.
Stull R B 1976 Internal gravity waves generated by penetrative convection; J. Atmos. Sci. 33 1279-1286.

Taylor L L 1979 Mesospheric heating due to intense tropical convection; NASA Contractor Rep. 3132, NASA, Washington DC.

Taylor M J and Hapgood M A 1988 Identification of a thunderstorm as a source of short period gravity waves in the upper atmospheric nightglow emissions; Planet. Space Sci. 36 975-985.

Tsuda T, Inoue T, Fritts D C, Vanzandt T E, Kato S, Satoand T and Fukao S 1989 MST radar observations of a saturated gravity wave spectrum; J. Atmos. Sci. 46 2440-2447.

Walterscheid R L, Schubert G and Brinkman D G 2003 Acoustic waves in the upper mesosphere and lower thermosphere generated by deep tropical convection; J. Geophys. Res. 108 1392-1397.

Worthington R M 1998 Tropopausal turbulence caused by the breaking of mountain waves; J. Atmos. Sol.-Terr. Phys. 60 1543-1547.

Worthington R M and Thomas L 1997 Impact of the tropopause on upward propagation of mountain waves; Geophys. Res. Lett. 24(9) 1071-1074.

Yoe G J, Larsen M F and Zipser E J 1992 VHF wind-profiler data and comparison of methods for detecting horizontal and vertical air motions in a mesoscale convective storm; J. Atmos. Oceanic. Technol. 9 713-727. 